\title{
Microbial Seed Coating-An Emerging Strategy towards Organic Vegetable Production: A Review
}

\author{
M. Rahman, H.S. Dutta
}

10.18805/ag.R-2272

\begin{abstract}
New revolutions have been taking place in agriculture since pre-historic times to increase agricultural production and meet the demands of rising population. The last revolution or green revolution has increased the overall production of all agricultural components but has led to several long-term environmental problems. Almost $62 \%$ of vegetables and $82 \%$ of fruits are found to have pesticide residues, which can affect our health in different ways. This have arisen the fear of eating raw fruits and vegetables and led to sublethal effects on natural enemies and pollinators. So, it is the very need of hour to look for sustainable approaches to control the plant diseases. Most of the plant pathogens are seed borne and disseminated. Thus, they affect the plants during pre-emergence stage or cause seedling damping off resulting in $100 \%$ crop loss. Under sustainable practices, microbial seed coating is an evolving precision technology. It enhances the shelf-life and activity of beneficial microbes and thereby decrease the use of harmful chemical pesticides and fertilizers. Natural products such as biochar, chitosan, peat, acacia gum, natural dyes from flowers Phutuka, Polash, Khoyar, Kodam can be used to manufacture microbial seed coats manually. Agribusiness firms Incotec, Novozymes and Monsanto have also led to developing of coated seeds laced with promising microbes. Thus, adoption of microbial seed coating can be a cost effective and efficient strategy in organic horticultural production.
\end{abstract}

Key words: Microbial seed coating, Precision technology, Sustainable practices.

Towards the end of 1800 s, the world population rose to 1 billion and by the end of 1930 it reached 2 billion. This rising population has led to innovation of new revolutions in agriculture since early times to feed the expanding world. The $3^{\text {rd }}$ revolution or "Green Revolution" has lessened the problem of population hunger, but it has led to several longterm environmental problems including ecosystem degradation in the post GR decades. Along the various programmes under green revolution, one of the most important was developing of high yielding variety seeds. These HYV were more responsive to chemical pesticides and inorganic fertilizers. Since then, growers started over and repeated use of these chemicals in the cultivation of fruits vegetables and other agricultural crops. Now it has been quite alarming how harmful these chemicals can be to human, plant and environment.

Residues of pesticide sprayed fruits and vegetables remain intact on them for a long period of time, till they reach grocery stores and finally our homes. Food and Drug Administration pesticide monitoring authority reported that almost $62 \%$ of vegetables and $82 \%$ of fruits a contaminated with pesticides in the market and the major group of pesticide found to be present is Dithiocarbonate. According to studies of World Environmental Group, the most 10 contaminated food items include strawberries, Spinach, Nectarines, Apples, Grapes, Peaches, Cherries Pears, Tomatoes, Celery. They are not easily washed away under plain water. When we intake these chemicals along with the raw fruits and vegetables that we consume, they get circulated in our body through the blood system. Scientists at the University of North Carolina revealed 300 different pesticide groups found in the discs of human
Department of Plant Pathology, Assam Agricultural University, Jorhat-785 013, Assam, India.

${ }^{1}$ Department of Horticulture, Assam Agricultural University, Jorhat785 013, Assam, India.

Corresponding Author: M. Rahman, Department of Plant Pathology, Assam Agricultural University, Jorhat-785 013, Assam, India.

Email: mehjebinr@gmail.com

How to cite this article: Rahman, M. and Dutta, H.S. (2022). Microbial Seed Coating-An Emerging Strategy towards Organic Vegetable Production: A Review. Agricultural Reviews. DOI: $10.18805 /$ ag.R-2272.

Submitted: 22-05-2021 Accepted: 14-01-2022 Online: 03-03-2022

brain cells. They damage our brain cells and neurons producing symptoms like Autism and Alzheimer's.

Pesticides are not only reported to affect human health, but they also disturb the ecosystem to a great extent. They have indirect or sublethal effects in the natural enemies, such as delayed adult emergence or decreased natural enemy survival. Fungicides at sub lethal concentrations reduces egg hatching ability and oviposition of the adults. Hence, they affect the fertility rate of females. Cloyd in 2008 reported in his article Mancozeb reduces egg-hatching of Amblyseius andersonii and parasitism rate of the caterpillar parasitoid, Trichogramma cacoeciae by 100 percent. Again, Dirceu et al. (2010) observed in their experiment both Mancozeb and Thiophanate-methyl have sterilising effects on females of predatory mite, Typhlodromus pyri.

Repeated application of pesticides causes accumulation of the recalcitrant chemicals in the upper layers 
of soil hampering the micro-biological (Muñoz-Leoz et al. 2011; Wang et al. 2012), biochemical activities (Wang et al. 2009), structutural integrity (You et al. 2016) and genetic diversity (Yen et al. 2009; Gu et al. 2010) thus leading to decline of beneficial soil microorganisms population in soil. Studies have shown that Oxytetracycline or Captan affect negatively in non-target soil microorganisms and their activities. For instance, Chlorpyrifos at $10-300 \mu \mathrm{g} \mathrm{g}^{-1}$ decreases the total number of bacteria in loamy soil. (Martinez-Toledo et al. 1992). Demethylation inhibitors (DMIs) such as triazoles (Verweij et al. 2009) are the most commonly used fungicides in orchards. These fungicides inhibit the synthesis of fungal ergosterol which alters fungal populations (Amer et al. 2007). Multiple application of DMI fungicide also reduces fungal sensitivity to the fungicide. Further, next generation DMI fungicide-triazole tetraconazole is used to replace the ineffective fungicides (Holb and Schnabel 2007; Verweij et al. 2009). However, persistent use of tetraconazole indicates a tendency to accumulate in the soil which is harmful for near future (Council Directive 2009).

Earlier it was assumed and accepted that fungicide has low phytotoxicity but with the detailed study of cell apparatus of plants treated with fungicides have shown damage in photosynthetic apparatus, decreased $\mathrm{CO}_{2}$ assimilation, perturbation of reproductive organ development. It has been observed that chlorophyll a fluorescence parameter, light reactions of photosynthesis, electron transport reactions of chloroplasts are affected by fungicide exposure (Amer et al., 2007; Ahmed et al., 1983; Petit et al., 2008).

Pesticides are a potent driver for loss of important pollinators. A bee flying through a pesticidal spray cloud in fields has $100 \%$ probability getting sprayed with the pesticide. A very minute amount i.e., Captan 215 ug/bee in contact and $91 \mathrm{ug} / \mathrm{bee}$ oral, carbendanzim $50 \mathrm{ug} / \mathrm{bee}$ contact can bring changes in the behaviour of bees. As a bee moves back to its hive, it carries the pesticide residues with it and spread among its brood causing a threat to the whole population (Basu et al., 2015).

Its high time that we should move on for sustainable or organic practices which will not have any adverse effects on the environment. Thus, designing the blueprint of horticulture in the coming years needs to direct focuses on sustainable approaches which enhance the yield of plants, protect plants while still maintaining the ecological balance.

\section{Importance of seed borne diseases}

It is very needful to maintain pathogen free seeds for organic agriculture as seeds are common carrier of plant pathogens (Senthamarai et al., 2011). Over 200 diseases have been reported to affect the different vegetables in the world. Among them the seed-borne pathogens mostly fungi play a vital role in disease development (Hossain et al., 2015). Fungal pathogens viz. Fusarium, Rhizoctonia, Verticillium, Sclerotinia and Macrophomina phaseolina cause a massive monetary loss each year. Moreover, a sudden hike of 19 $90 \%$ damping off incidence was reported with increasing inoculum levels of Rhizoctonia solani, while the incidence of root rots caused 10 to $80 \%$ losses in different vegetables. (Shafique et al., 2016). Major soil borne diseases of horticultural crops that affects crop at seedling stage or cause pre-emergence damping off are Fusarium wilt of melon, Phytophthora blight and fruit rot of pepper, Pythium damping off pepper, White mold of cabbage, Rhizoctonia root and hypocotyl rot of radishes, Bacterial wilt of tomato. Again, there are many severe seed borne diseases which are difficult to control if not taken proper care at the early stages viz., Fusarium wilt of tomato, Phomopsis blight of brinjal, Black leg of cabbage, Botrytis Neck rot of onion, Black rot of cabbage, Fusarium wilt of melon etc.

\section{Organic practices for seed borne diseases}

Various organic practices recommended for seed borne diseases are: seed treatments, proper seed storage, variety selection ang grafting, organic amendments, optimum plant spacing and sanitation.

\section{Seed coating}

Seed coating is the application of exogenous materials onto the surface of seeds with the aim of improving seed appearance and handling characteristics (e.g., seed weight and size) and or delivering active compounds (e.g., plant growth regulators, micronutrients and microbial inoculants) that can protect the seed against phytopathogens and increase germination and plant growth (Halmer, 2008; Pedrini et al., 2017).

Today seed coating has been well adopted by horticultural and crop industries globe wide and has earned its place in the international market for applying colours as tracers, protectants, soil adjuvants, micronutrients. Horticultural crops in which seed coating technology has been applied for various purposes are onion, tomato, lettuce, chilli, okra, sunflower, watermon.

\section{Types of seed coating}

Seed dressing is the application of finely milled solid dusts onto surface of seeds in small amounts.

Film coating is a technique of encapsulating seeds with a thin layer of slurry prepared from polymers, plasticizers, pigments or solvents and with the help of a rotating drum machines. The thin coating layer does not greatly change the size or shape of seeds, but it enhances the handling characteristics of seeds and at the same time eliminates or minimizes input dust-off (e.g., pesticides, biological and micronutrients) (Taylor et al., 2001).

Pelleting is the process of coating seeds with inert materials (e.g., calcium peroxide, talc, bentonite, sand and diatomaceous earth) in order to enable or enhance precise seed placing by modifying their shape, size and weight. It turns thin seeds into larger, spherical shaped seeds, which can be placed easily in the field (Zhang et al. 2009).

Encrusting is the process of covering seeds with a small amount of adhesive and inert material to empower precise mechanical seed metering. It built a smoother surface, more uniform shape and increases size and weight of seeds that 
can be used in the greenhouse or the field, thus enhancing seed sowing/planting efficiency (Szemruch and Ferrari, 2013). This method is mostly adopted on crops requiring single placement of seeds and not requiring post-emergence thinning (Rui et al., 2016). Encrusting results more weight of seeds as compared to film coating and significantly lesser weight than pelleting, which is more economical compared to pelleting.

\section{Components of seed coating}

Seed: Disease free clean seeds should be used. According to the type of seeds, proper sterilization protocol should be followed to sterilize it.

Microbial inoculum: Microbes such as Trichoderma, Pseudomonas, Bacillus which have both plant growth promoting and plant protecting attributes can be used in seed coating.

Binder: Binder is used as an adhesive material to adhere the microbial inoculums and other additives to the seed. Natural products such as Gum Arabic, Xanthan Gum, CMC and alginate beads can be used. Xanthan gum can be obtained by bacterial fermentation of simple sugar. Alginate beads are extracted from seaweeds. Gum Arabic is a natural resin secreted by the Acacia tree. Dawar et al. (2008) conducted a research to test the effect of coating agents on efficacy of microbial antagonists in the crop okra and sunflower. Sugar, mollases, glucose and gum arabic were used as adhesives at $1 \%$ and $2 \%$ concentration. The $2 \%$ gum Arabic solution showed more promising results in increasing shoot length, shoot weight, root length, root weight and in reducing infection of root rot fungi viz., $M$. phaseolina, R. solani and Fusarium spp., on okra.

Filler: Fillers are substances used for increasing the bulk density of seeds. Natural substances such as peat, talc, chitosan and biochar can be used instead of using synthetic polymers. Chitosan is obtained by solubilizing the shell of crustacean insects viz., shrimps, crabs. Biochar is charcoal from plant matter very rich in organic source.

\section{Seed coating agents}

Along with the beneficial microbes, seeds can be supplied with other essential elements such as micronutrients, growth stimulators (humic acid, algae extracts, phytohormones) according to the need of the crop. Seeds can be traced by using some natural dyes extracted from flowers (Acacia catechu, Adinia cordifolia, Albizia odoratissima, Basella alba, Butea monosperma) instead of using synthetic dyes.

\section{Diversified role of microbes applied in seed coat}

Plant Beneficial Microbes (PBM) applied in a seed coat play several roles from promoting seed germination, seedling establishment to protecting the plant from different insect pest. They are also good rhizomediators.

Leaves are the source for preparing photosynthates in plants. These photosynthates viz., carbohydrates, amino acids get accumulated in the roots which acts as signal to different pathogens and beneficial microbes in the rhizosphere. Microbes present in the seed coat are well provided with its food source and a suitable microenvironment which are extendedly released from the seed coats. The cell membrane of bacterial cells is negatively charged which binds alternatively with the basic and acidic electrolytes present in the seed coat thus facilitates extended release of microbes. Now, the seed has enough number of good microbes which can easily compete the pathogenic microbes for food and space. They also secrete lytic enzymes, volatile organic compounds (VOCs), antibiotics, hydrogen cyanide $(\mathrm{HCN})$ which are toxic to the pathogenic microbes. Also, PBM initiate Induced Systemic Resistance (ISR) which is an indirect mechanism to prevent disease occurrences in plants. Plant growth promoting microbes (PGMP) fixes nitrogen; solubilizes phosphorus, potassium; make available different vitamins and minerals to the plant; secretes various phytohormones, thus promoting seed germination, seedling establishment and growth of the plant.

\section{Drawbacks of biopesticides in the field}

When biocontrol agents (BCA) are released in the field, they may be affected by several environmental factors such as soil $\mathrm{pH}$, temperature, moisture. The early stage of a bacteria is the lag phase in which they require proper food and environmental condition to adjust in the new environment. After successfully completing the lag phase, they reach the log phase where they double their population and have the highest metabolic activities. But if the lag phase is affected, beneficial microbes applied in the field will decline. Also, UV radiations, soil erosion, wind erosion may also degrade these beneficial microbes. Thus, many a times we often come up with negative results when using the biopesticidal products in field or the results are not as effective as in lab.

\section{Advantage of microbial seed coat}

Microbial seed coating is an approach to precision farming which is knowledge based, ecologically and economically significant. This technology helps protecting the seeds from pests and diseases during storage. Also, during germination, the roots of the plant will have all the beneficial microbes in the rhizosphere from seed coat for proper germination and heathy plant growth. Kumar et al. (2015) developed seed coating formulation where they applied consortium of Bacillus subtilis OTPB1 and Trichoderma harzianum OTPB3 strains in vegetable seeds. Coated seeds with microbial consortium and vermicompost (T3) gave the best results in all parameters of seedlings growth and induction of three defence enzyme activities (polyphenol oxidase, peroxidase, superoxide dismutase). Thus, seed coating provides PBM to a plant in the right place and right amount. Other supplements provided in the seed coat protects from adverse environmental conditions and UV rays. They facilitate the extended release of microbes and enhance the function of PGPM. Yogeesha et al. (2017) standardized protocol for seed pelleting in onion with two micronutrients (zinc sulphate $5 \%$, boric acid $1 \%$ ) and two microbial consortia (Microbial 
consortium I: Actinomycetes+Bacillus aryabhatai, Microbial consortium II: Bacillus subtilis+Trichoderma harizianum). Methyl cellulose $(1.5 \%)$ and polyvinyl alcohol $(2.0 \%)$ were sprayed uniformly on seed surface in very fine droplets as an adhesive material. Cow dung, vermicompost, clay soil in the ratio of 3:2:1 volume basis was put manually layer after layer till the desired pellet size was achieved. Pelleted seeds $\left(4.3 \times 10^{4} / 50\right.$ pelleted seeds) have shown good amount of population count as compared to control $\left(0.6 \times 10^{4} / 50\right.$ pelleted seeds) after 3 months storage along with highest crop stand, bulb percentage, bulb weight, yield. Hence, a rich seed and soil microbiome will promote a healthy plant microbiome which in turn will help the population to consume pesticide free, rich in organic matter fruits and vegetables.

\section{CONCLUSION}

It is a largely untapped area that deserves much research and development. Microbial seed coating has a great potential to overcome several lacunas that we face in other biocontrol practices. Different supplements like phytohormones, micronutrients, biocontrol agents, plant growth promoting micro-organisms, algal extracts, natural dyes (for identification), humic acid can be incorporated at once along with the seed as required by a particular crop. Application of natural binders and food for microbes such carboxy methyl cellulose (CMC), chitosan, biochar, xanthan gum helps to protect the microbes and increase their shelflife. Also, this technology is highly time saving and cost effective. Labour input in field is reduced as spraying of fertilizer, pesticides can be avoided. Goal has been set in respect of the International seed coating market to reach a CAGR of $8.10 \%$ and market size of USD4.287 billion in 2025 from a market size of USD2.686 billion in 2019. Agribusiness firms Incotec, Novozymes, Monsanto which were earlier hugely investing in chemical pesticides have now started field-testing of seeds laced with promising microbes. Incotec in North America have developed microbial seed coating in lettuce, onion, parsnip etc which have compliant with the requirements of federal regulatory program National Organic Program (NOP). The motive is to help their customers and farmers choose to grow their crops organically. They have committed to offer an alternative organic solution for more $90 \%$ of vegetable crops by 2021 .

\section{Future directions}

Microbial seed coating has been highly done in field crops especially leguminous crops. It is still in nascent stage in case of horticultural crops. But there is high potential for developing seed coating with microbes in vegetables and flower crops. Several researches have been done in laboratories which needs to be carried to the field. It is also a new direction for skill development and entrepreneurship among the youth and women. Once, we see the feasibility of this organic approach in field we need to disseminate the technology among farmers, Agri firms, extension workers etc.

Conflict of interest: None.

\section{REFERENCES}

Ahmed, M.M., Heikal, D. and Hindawy, O.S. (1983). Side effects of benomyl (Fungicide) treatments on sunflower, cotton and cowpea plants. Phyton. 23: 185-195.

Amer, M.M. Shehata, M.A., Lotfy, H.M., Monir, H.H. and Yakugaku, Z. (2007). Determination of tetraconazole and diniconazole fungicide residues in tomatoes and green beans by capillary gas chromatography. Journal of the Pharmaceutical Society of Japan. 127(6): 993-9.

Basu, P., Basu, C. and Priya Darshini. (2015). Sub-lethal effects of pesticides on pollinators with special reference to honeybees. In: Mutualistic Interaction between Flowering Plants and Animals. Publisher: Manipal University Press.

Council Directive 2009/82/EC of 13 July 2009 amending directive 91/414/EEC to include tetraconazole as an active substance. Off J Eur Union. 2009; 196: 10-13.

Dawar, S., Hayat, S., Anis, M., and Zaki, M.J. (2008). Effect of seed coating material in the efficacy of microbial antagonists for the control of root rot fungi on okra and sunflower. Pakistan Journal of Botany.

Dirceu, P. andré, M.M., Wagner, F.B., Flávio, N.C., Gilberto, S.A. and Ricardo, A.P. (2010). Side effects of fungicides used in cucurbitaceous crop on trichogramma atopovirilia oatman and platner (hymenoptera: trichogramatidae). Chilean Journal of Agricultural Research. 70: 323-327.

Gu, L., Bai Z., Jin, B., Hu, Q., Wang, H., Zhuang, G. and Zhang, H. 2010. Assessing the impact of fungicide enostroburin application on bacterial community in wheat phyllosphere. Journal of Environmental Science (China). 22(1): 134-41.

Halmer, P. (2008). Seed technology and seed enhancement. Acta Hortic. 771: 17-26.

Holb, I.J. and Schnabel, G. (2007). Differential effect of triazoles on mycelial growth and disease measurements of Monilinia fructicola isolates with reduced sensitivity to DMI fungicides. Crop Protection. 26: 753-759.

Hossain, G.M.K., Ahsan, S.M. and Ahmed, T. (2015). Prevalence of seed-borne fungi of different vegetables seeds in Bangladesh. Asian Journal of Medical and Biology Research. 1(3): 628-640.

Kumar, S., Chowdappa, P. and Krishna, V. (2015). Development of seed coating formulation using consortium of Bacillus subtilis OTPB1 and Trichoderma harzianum OTPB3 for plant growth promotion and induction of systemic resistance in field and horticultural crops. Indian Phytopathology. 68: 25-31.

Ma, Y. (2001). Seed coating with beneficial microorganisms for precision agriculture. Biotechnology Advances. 1537(7): 107423.

Martinez-Toledo, M.V., Salmeron, V. and Gonzalez-Lopez, J. (1992). Effect of insecticides methylpyrimifos and chlorpyrifos on soil microflora in an agricultural loam. Plant Soil. 47:2 5-30.

Muñoz-Leoz, B., Ruiz-Romera, E., Antigüedad, I. and Garbisu, C. (2011). Tebuconazole application decreases soil microbial biomass and activity. Soil Biology and Biochemistry. 43: 2176-2183.

Pedrini, S., Merritt, D.J., Stevens, J. and Dixon, K. (2017). Seed coating: Science or marketing spin? Trends in Plant Science. 22: 106-116. 
Petit, A.N., Fontaine, F. Clement, C. and Vaillant-Gaveau, N. (2008). Photosynthesis limitations of grapevine after treatment with the fungicide fludioxonil. Journal of Agricultural and Food Chemistry. 56(15): 6761-6767.

Rui, S., Oliveira, I.R., Ying, M., Miroslav, V. and Helena, F. (2016). Seed coating with arbuscular mycorrhizal fungi as an ecotechnologicalapproach for sustainable agricultural production of common wheat (Triticum aestivum L.), Journal of Toxicology and Environmental Health, PartA, 79(7): 329-337.

Senthamarai, M.P., Subramanian, K.S. and Sudheer, M.J. (2011). Nematode fungal disease complex involving Meloidogyne incognita and Macrophomina phaseolina on medicinal coleus, Coleus forskohlii Briq. Indian Journal of Nematology. 38(1): 30-33.

Shafique, H.A., Sultana V., Ehteshamul-Haque S. and Athar, M. (2016). Management of soil-borne diseases of organic vegetables. Journal of Plant Protection Research. 56(3): 221-230.

Szemruch, C.L. and Ferrari, L. (2013). Encrusting offers protection against phytotoxic chemicals and maintains the physiological quality of sunflower (Helianthus annuus) seeds. Seed Science and Technology. 41(1): 125-132.

Taylor, A.G., Eckendrode C.J. and Straub, R.W. (2001). Seed coating technologies and treatments for onion: challenges and progress. HortScience. 36(2): 199-205.

Untiedt, R. and Blanke, M.M. (2004). Effects of fungicide and insecticide mixtures on apple tree canopy photosynthesis, dark respiration and carbon economy. Crop Protection. 23(10): 1001-1006.
Verweij, P.E., Snelders E., Kema G.H., Mellado, E. and Melchers, W.J., Lance. (2009). Azole resistance in Aspergillus fumigatus: a side-effect of environmental fungicide use? Infectious Disease. 9(12): 789-95.

Wang, Q.Y., Zhou, D.M. and Cang, L. (2009). Microbial and enzyme properties of apple orchard soil as affected by long-term application of copper fungicide. Soil Biology and Biochemistry. 41:1504-1509.

Wang, X., Song, M., Wang, Y., Gao, C., Zhang, Q., Chu, X., Fang, H. and Yu, Y. (2012). Response of soil bacterial community to repeated applications of carbendazim. Ecotoxicology and Environmental Safety. 75(1): 33-9.

Yen, J.H., Chang, J.S., Huang, P.J. and Wang, Y.S. (2009). Effects of fungicides triadimefon and propiconazole on soil bacterial communities. Journal of Environmental Science and Health B. 44(7): 681-689.

Yogeesha, H.S., Panneerselvam, P., Bhanuprakash K. and Hebbar, S.S. (2017). Standardization of protocol for seed pelleting in onion (Allium cepa) to improve seed handling. Indian Journal of Agricultural Sciences. 87(7): 975-80.

You, C., Zhang, C. and Kong, F. (2016). Comparison of the effects of biocontrol agent Bacillus subtilis and fungicide metalaxyl-mancozeb on bacterial communities in tobacco rhizospheric soil. Ecological Engineering. 91: 119-125.

Zhang, J.X., Xue, A.G. and Tambong, J.T. (2009). Evaluation of seed and soil treatments with novel Bacillus subtilis strains for control of soybean root rot caused by Fusarium oxysporum and F. graminearum. Plant Diseases. 93: 1317-1323. 